\title{
Validation of a Business Model for Cultural Heritage Institutions
}

\author{
Cristian CIUREA ${ }^{1}$, Florin Gheorghe FILIP ${ }^{2}$ \\ ${ }^{1}$ Bucharest University of Economic Studies, Bucharest, Romania \\ ${ }^{2}$ Romanian Academy- INCE \& BAR, Bucharest, Romania \\ cristian.ciurea@ie.ase.ro,ffilip@acad.ro
}

The paper proposes a business model for the efficiency optimization of the interaction between all actors involved in cultural heritage sector, such as galleries, libraries, archives and museums (GLAM). The validation of the business model is subject of analyses and implementations in a real environment made by different cultural institutions. The implementation of virtual exhibitions on mobile devices is described and analyzed as a key factor for increasing the cultural heritage visibility. New perspectives on the development of virtual exhibitions for mobile devices are considered. A study on the number of visitors of cultural institutions is carried out and ways to increase the number of visitors are described.

Keywords: Cultural Heritage, Virtual Exhibitions, Business Model, Mobile Applications, Validation

\section{Introduction}

As previous presented in [1], we are living in the era of the internet and mobile technologies, where information can be accessible at a touch/click distance and the most important is that the access can be anytime and from anywhere. Mobile technologies have evolved at exponential rate in the last years and the evolution will continue. The rapid change of mobile devices in hardware and software have made possible the replacement of old computers and laptops with smart phones and tablets when discussing about internet surfing, email checking and so on [2].

Young people represent the majority of mobile device users, having grown up with these gadgets and being familiar with their use. A big issue of the anytime-anywhere access to information of young people is that they want to discover everything online, they have no time to go to libraries to read classic books, they are not willing to visit museums and art galleries to explore exhibitions of paintings, sculptures and so on. Thus, their knowledge of culture, literature and history is not as rich as schools and universities expected them to have.

In order to aid the young generation and to increase the visibility and number of visitors, libraries and museums have decided to present their exhibitions and collections online. The idea of virtual exhibitions implementation on mobile devices, as native mobile applications, is accepted by many museums and libraries that already have digitized material available online. A virtual exhibition goes beyond digitizing a collection which is primarily meant for preservation [3]. Digital exhibitions need digital storytelling, which is one way for cultural heritage institutions to give new meaning to an object and to create a captivating story around it. The real exhibitions can serve as the starting point for digital storytelling applications. Digitized objects that will be embedded in a storytelling application must be chosen with care, because not all objects in an exhibition are suitable for a digital storytelling project [4].

The potential offered by mobile technologies and the increased number of mobile devices processing multimedia content, both offline and online, facilitate the implementation of virtual exhibitions on mobile devices [5]. In [6] and [7], a cybernetic model for computerization of the cultural heritage is proposed in order to study the relationship between the organizations involved.

Over the past two decades, the technological development, such as innovative hardware and software, information retrieval channels, mobile devices, had a great economic and social impact on our lives. They have 
radically changed the way we find and receive our information and, most importantly, the way how we communicate [5].

As considered in [8], the cultural heritage represent a significant power for the current century in Europe. The cultural heritage is the heart of what it means to be European and it is now discovered by both governmental institutions and citizens as a solution of improving economic performance and people's lives.

The current paper is an extended version of the work presented at the 14th International Conference on Informatics in Economy, IE 2015, 30 April - 03 May 2015, Bucharest, Romania [1].

\section{Economy of Culture}

The idea of economy of culture originated in the 90s, when De Michelis said that "Europe's cultural heritage is a strategic resource similar to oil for Arab countries". Through the digitization process of multimedia collections from libraries, museums and other cultural institutions, the knowledge and development of national and European cultural heritage elements are ensured [6].

The economy of culture is a combination of technological developments, human factor, new business models and geopolitical and economic evolutions [9], as shown in Figure 1.

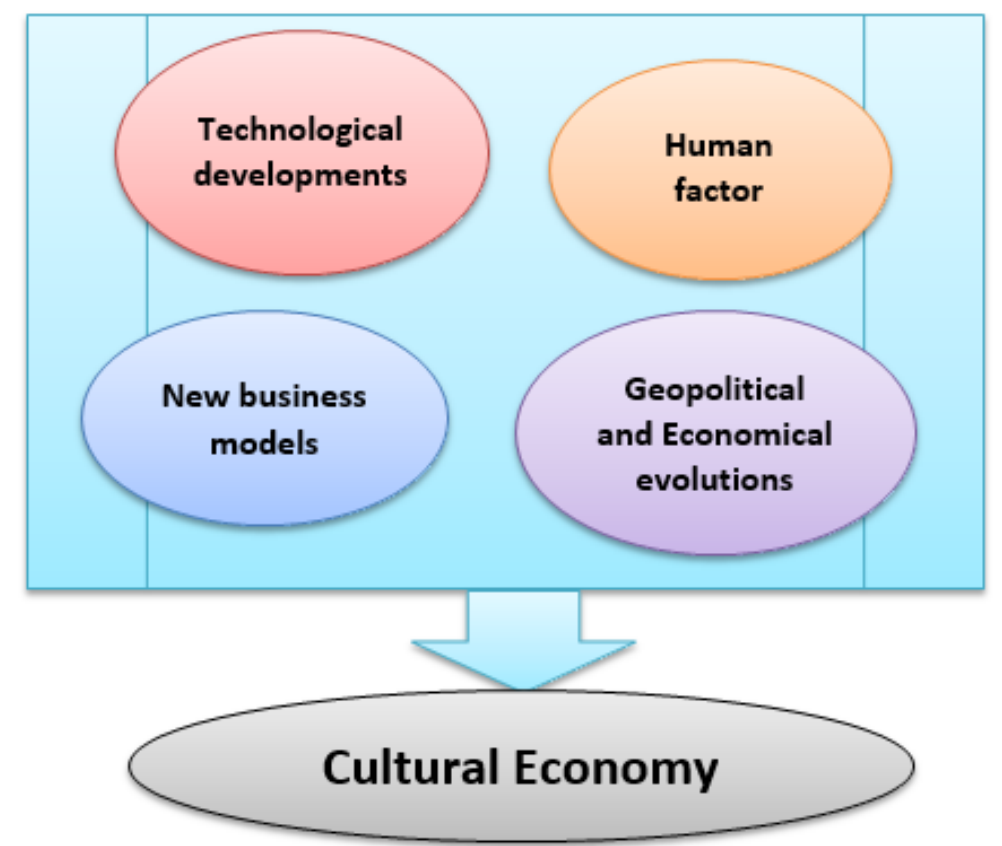

Fig. 1. Economy of culture components

When discussing about economy of culture, we must consider the academic world's perspective on democratization of the access to knowledge and on preservation of the original objects of cultural heritage.

At the same time, heritage and culture in a globalized world are exposed to a wide range of demands of consumption and communication [10].

The evolution of information and communication technologies must ensure not only a better knowledge and preservation of cultural heritage items, but it must promise an increased number of direct visitors of cultural institutions as well. Software applications for creating virtual exhibitions, in addition to being used as tools to prepare and build content for virtual visits, may help the staff of a museum or library to conceive and create exhibitions [11].

Technology has offered museums and libraries the means to create more vivid and attractive presentations for 
communicating their message to the visitors in a more effective and attractive manner [12].

When it comes to work on cultural heritage, on these days the digitization of cultural collections is determined as another major concern of European cultural heritage institutions. The advantages of turning physical objects into digitals are obvious: it prevents them from destruction, it provides opportunities that not existed before. Furthermore, the collections of different institutions can be compiled in large centralized archives and databases that allow collaborative access and more efficient working.

Digital preservation is in progress, too: more and more components of our cultural heritage are transformed into digital formats. One of the biggest challenges here is to ensure adequate representation and long-term access to the created digital information considering the standards and the user habits that are under permanent change [4].

\section{Study about Visitors' Number of Cultural Institutions}

We live in the information era, where people are bombarded with a lot of information about everything. It appears the phenomenon of "infobesity" and "infotoxication" [13] and people must be able to select the information they need to consume. In many situations, it is very important to have the power to decide if will be better to read a book, for example, or to see a movie. Both of them are transmitting a message, but one can be more educational than the other. Also, it is important to decide if you prefer to read an article from a blog or to check the Facebook newsfeed.

The situation is similar when people are deciding to spend their time to visit a museum or library or to do something else that will offer them a satisfaction. Museums and libraries are confronted with a situation that they never meet before. They must be competitive on the information market, in order to survive and attract many visitors that will bring them revenues. Recent studies and surveys demonstrated that visitors of museums and libraries have an increased educational level. So, visitors know very well what they do when they decide to visit a museum. Other surveys shows that museums' visits are in many cases a shared experience with the life partner or with friends, and only $30 \%$ are unaccompanied visits [4].

When discussing about how to increase the number of museums and libraries visitors, we can take into consideration innovative economic models for increasing audience. As mentioned before, many of visitors are with high educational level and only a few part is represented by normal people. The way in which these cultural institutions can increase their number of visitors is to re-attract the existing visitors and to target a big mass of visitors that never been there before.

But, in order to attract such special visitors, museums and libraries must offer them a preview of their most valuable collections. So in this way the visitors can choose what museum to visit. In the knowledge-based society we are living it is mandatory for museums and libraries to digitize their collections and present them online, in a virtual exhibition format. Other recent studies presented that $57 \%$ of Europe cultural heritage needs digitization until the year 2040 [4]. This means that museums and libraries have a lot of work to do with the digitization process of their collections.

Virtual exhibitions need standardization in order to be counted and measured. The Digital Exhibitions Working Group (http://museumsdokumentation.de/joomla) created a standard for support the identification and selection of digital exhibitions by the interested visitors. This standard is called DEMES - Digital Exhibition Metadata Element Set and includes a set of descriptive elements specific to digital exhibitions, grouped into seven semantic sections [25]. This standard facilitates data sharing information exchange about virtual exhibitions and enhances the current descriptive practice through standardization. 
Digitization created new opportunities for museums and libraries, which not existed before [22] [23]. In the digital era it is possible to create virtual exhibitions that include objects from collections stored in different museums or libraries around the world. For example, if a curator plan to organize a virtual exhibition with paintings of Picasso, then he can request access to all digitized Picasso paintings from different museums and build the virtual exhibition. The rights for the digital objects belong to the museums that provided the digital formats of Picasso paintings.

In Figure 2 is shown an example of virtual exhibition for mobile devices created by aggregation of digital objects from different museums around the world.

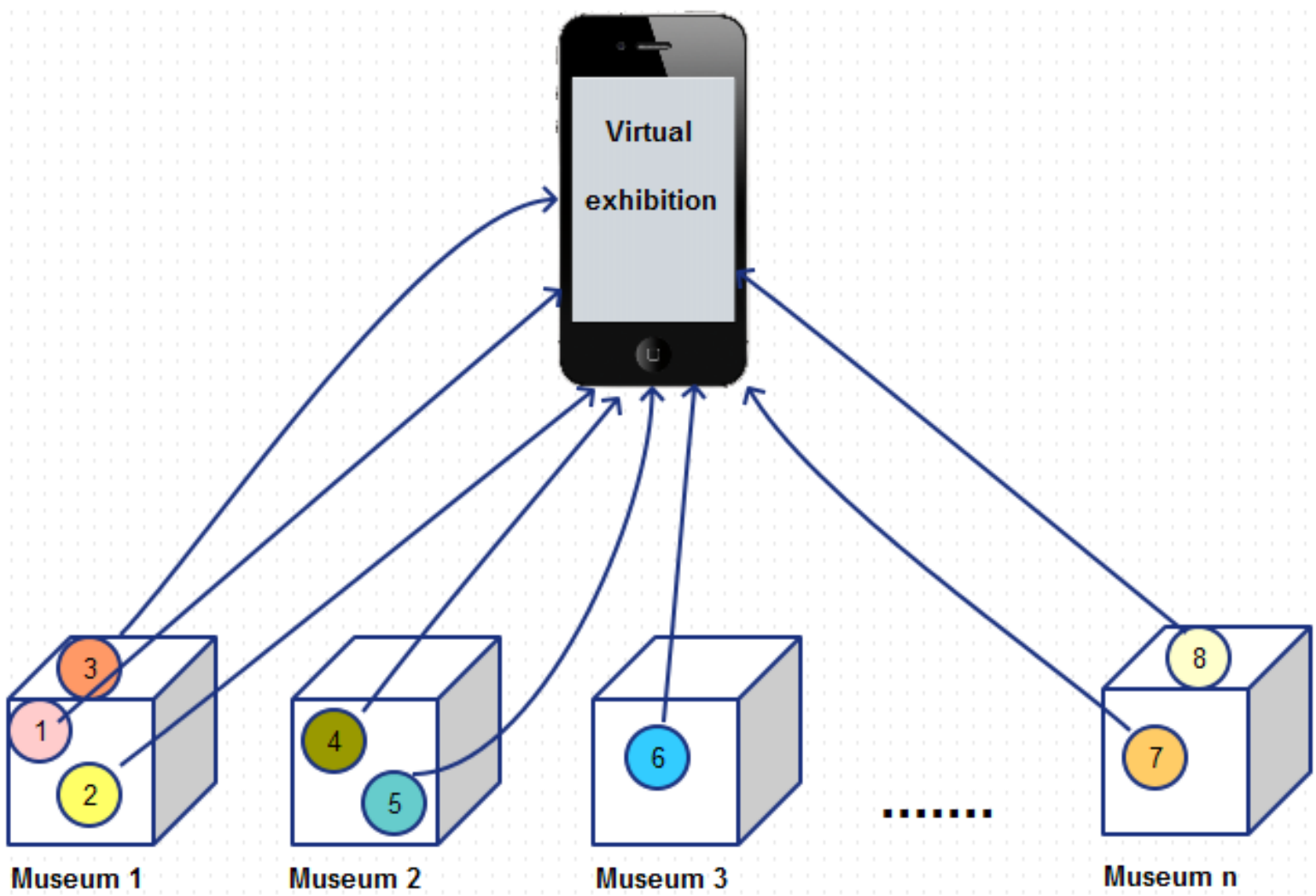

Fig. 2. Aggregation of digital objects from different museums in a mobile virtual exhibition

Regarding the visitors number of cultural institutions, it is not possible to count the number of unique visitors in all galleries, libraries, archives and museums around the world, because there are visitors that come repeatedly to the same museum or library. We can count the number of total visits in a period, but this includes many visits of the same visitors. In order to have an image about the number of unique visitors, cultural institutions are using different surveys, where visitors are asked to tell if they visited the museum or library for the first time or they are returning visitors. Some questions may refer to other museums and libraries they have already visited. In this way, we can estimate the number of unique visitors of some museum or library.

According to a study presented by Ms. Andrea Prehn from Institute for Museum Research in Berlin, the top ten museums in Berlin by number of visitors, in the year 2014, are shown in Table 1.

The top of museums is changing every year, depending on the number of visitors and the permanent and temporary exhibitions they present to the public. 
Table 1. Top 10 museums in Berlin by number of visitors

\begin{tabular}{|c|c|}
\hline Place & Name \\
\hline \#10 & Technical Museum in Berlin \\
\hline \#9 & Museum for Natural History \\
\hline \#8 & GSR Museum \\
\hline \#7 & Jewish Museum Berlin \\
\hline$\# 6$ & German Historical Museum \\
\hline \#5 & Wall museum Checkpoint Charlie \\
\hline$\# 4$ & Berlin Wall Memorial \\
\hline \#3 & Neues Museum \\
\hline \#2 & Topography of Terror Documentation Center \\
\hline$\# 1$ & Pergamon Museum \\
\hline
\end{tabular}

The digital era determined the increase of the visitors' number of cultural institutions, even if representatives from museums and libraries considered that if they will make available online digital formats of objects from important collections, then will decrease the number of visitors. This cannot be proved because there were many cases that demonstrated otherwise. Prof. Monika Hagedorn-Saupe from Institute for Museum Research in Berlin considered as example the Mona Lisa painting of Leonardo da Vinci, which appeared everywhere in digital format, but people still want to see it in reality at the Louvre museum.

Digital and virtual exhibitions have a disadvantage in terms of feelings and emotions they transmit to the visitors. In a real exhibition you can see the physical objects in their natural size, you can touch some of them and you can feel the air and the light sensations transmitted by the museum where the exhibition is located. This is a very important aspect when visitors are appreciating the quality of an exhibition. In a virtual exhibition you can have the sound and music presented in the physical one, but depends on the visitors in which place and moment they choose to explore the exhibition. In order to feel the emotions, if they have the possibility, the visitors of the virtual exhibitions will decide to see the real ones.

Another difference between real and virtual exhibitions is the way of interaction with visitors. Even if some interactions with visitors from a real exhibition can be simulated in the virtual exhibition, the sensation and user experience are not the same. For example, at Jewish Museum in Berlin you have the Rafael Roth Learning Center, created in September 2001 as a multimedia study center, which supplements the real exhibition with interactive programs. In this manner, images, videos, text and audio files are presented using various devices. Another example is given at Checkpoint Charlie Black-box in Berlin, where visitors of the real exhibition can use an automatic machine to take pictures, insert them in a post card and send them by email.

The ways of interaction with visitors are multiple, starting with displays with touchscreens where people can watch some films, continuing with playing some audio and video clips, interacting with a projected image on a wall and finishing by touching objects in the real exhibition. All these ways of interaction in a real exhibition make difficile the implementation of virtual exhibitions, especially on mobile devices, where user interaction possibilities are limited by size and capabilities.

\section{The Proposed Business Model}

The model proposed for explaining the interaction between actors of cultural heritage sector has the objective to highlight the direct relation between investment in digitization and visibility of cultural heritage exhibits on the one side, and the number of visitors and revenues of cultural institutions 
on the other side [14]. The model supposed to increase the visibility and attractiveness of different exhibits and collections stored in libraries and museums by making them available online with the support of mobile applications for the implementation of virtual exhibitions [15] [16].

The objective of implementing virtual exhibitions on mobile devices is not to replace physical exhibitions, but to bring art consumers closer to what they love, to make collections accessible at any time and from any place, to keep visitors informed in the field with new exhibitions or events and to open people's appetite to knowledge [17].

Here is the simplified business model:

$$
\begin{aligned}
& x_{1}(k)=\sum_{i=1}^{W} d_{i}(k)+\sum_{i=1}^{w} v_{i}(k)+x_{0}(k) \\
& y_{1}(k)=\sum_{i=1}^{w} m_{i}(k)+\sum_{i=1}^{w} h_{i}(k)+y_{0}(k)
\end{aligned}
$$

where:

$k$ - the current month;

$x_{1}$ - the number of estimated physical visitors of cultural institutions;

$x_{0}$ - the number of existing physical visitors of cultural institutions (who visit them repeatedly);

$d_{i}$ - the increase of the number of visitors resulting from investments in digitization; $v_{i}$ - the increase of the number of visitors resulting from investments in visibility (implementation of virtual exhibitions for mobile devices);

$y_{1}$ - the estimated revenue of cultural institutions;

$y_{0}-$ the current revenue of cultural institutions;

$m_{i}$ - the revenue resulting from investments

in visibility (development of virtual exhibitions for mobile devices);

$h_{i}$ - the revenue resulting from data reuse (digitized collections reuse);

$w$ - the number of exhibits selected for digitization;

$z$ - the number of digitized exhibits selected for reuse.

In Figure 3 below, there are presented the relations between implementation of virtual exhibitions for mobile devices on the number of visitors and revenues of galleries, libraries, archives and museums. The figure shows a simplified diagram of the proposed business model, in which users of mobile applications, such as virtual exhibitions, come to visit cultural institutions, due to exploration of virtual exhibition on the mobile device.

In the preconditions of the business model proposed, we consider that data should be reusable also for other virtual exhibitions or in other online way. The concept of permanent universal cultural depot appears, which is totally distributed, infinite in size and accessible anytime and anywhere and implementing the vision of the British novelist H. G. Wells [18]. 


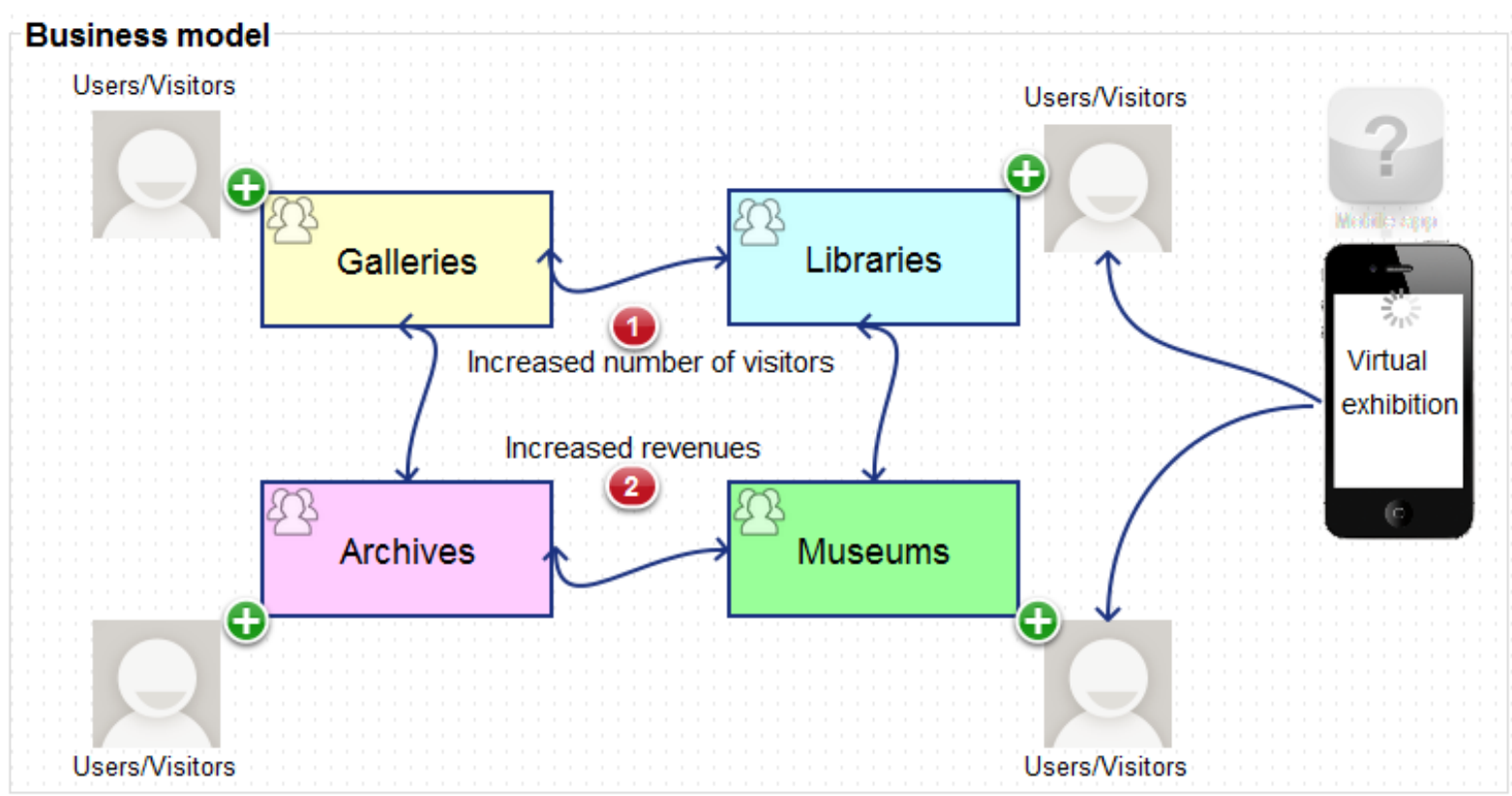

Fig. 3. Influence of business model on cultural institutions indicators

The impact of the business model is upon several other domains, such as education (increase the quality and attractiveness), tourism (diversification of the offer of services), e-commerce with digital content and consumer goods industry.

\section{A Mobile Application for Virtual Exhibitions}

We consider a mobile application for implementing a virtual exhibition accessible on mobile devices, such as tablets and smartphones with Android $($ ) operating system. The mobile application is designed to allow the reuse of digital content to implement also other virtual exhibitions. The whole digital content, such as images, movies, sound and text descriptions are stored on server and not locally, on mobile devices. This is a feature that allows the developer to change the content of the virtual exhibition, without requesting the user to update or reinstall the mobile application.

The mobile application created was meant to present a virtual exhibition with historical documents from the Romanian Academy Library (BAR). Some screen captures from the mobile application are displayed in Figure 4.

The mobile application has the following objectives:
- attract new visitors online, who will be transformed into physical visitors of cultural institutions;

- present most important pieces of collections extracted from real exhibitions;

- increase the visibility of collections shown in virtual exhibitions;

- estimate the users' behavior, in order to create categories of visitors and to discover users' preferences in terms of exhibits visited.

Providing educational and cultural information through virtual exhibitions on mobile devices is not enough to arouse the interest of young people in culture, as the collections need to be presented to the public in an attractive manner.

When digitized objects are aggregated and inserted in collections, each object receives a description by the museum or library that owns the object. There are many situations when the same object receives different descriptions, depending on the curator of the exhibition where the object is presented. Also, the same object can have multilingual descriptions, in different languages, depending on the country where the exhibition is realized. 


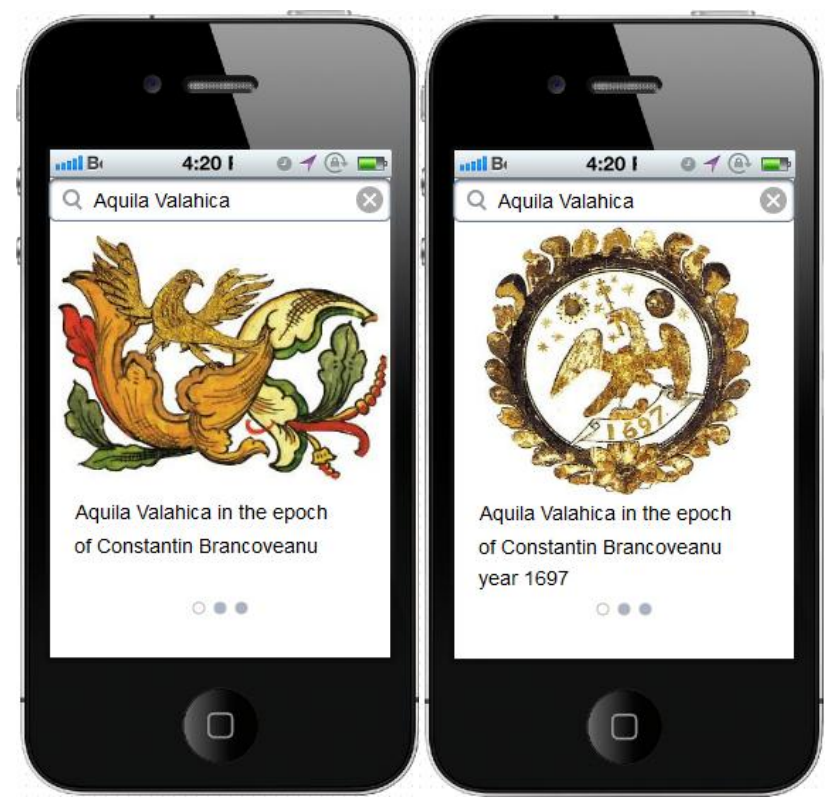

Fig. 4. Mobile application for virtual exhibition implementation

The authors think to implement the proposed business model, in the mobile based solution, by making available the mobile application to a great number of museums and libraries in Romania in order to collect and analyze information about the evolution of indicators. We have created a mobile application for implementing a virtual exhibition of first women of the Romanian Academy. The exhibition was presented also in physical format at Romanian Academy Library and, based on the existing digital material available for this topic, an Android mobile application was built by two students from the Faculty of Cybernetics, Statistics and Economic Informatics, under our guidance. Some screenshots of the application are shown in Figure 5.

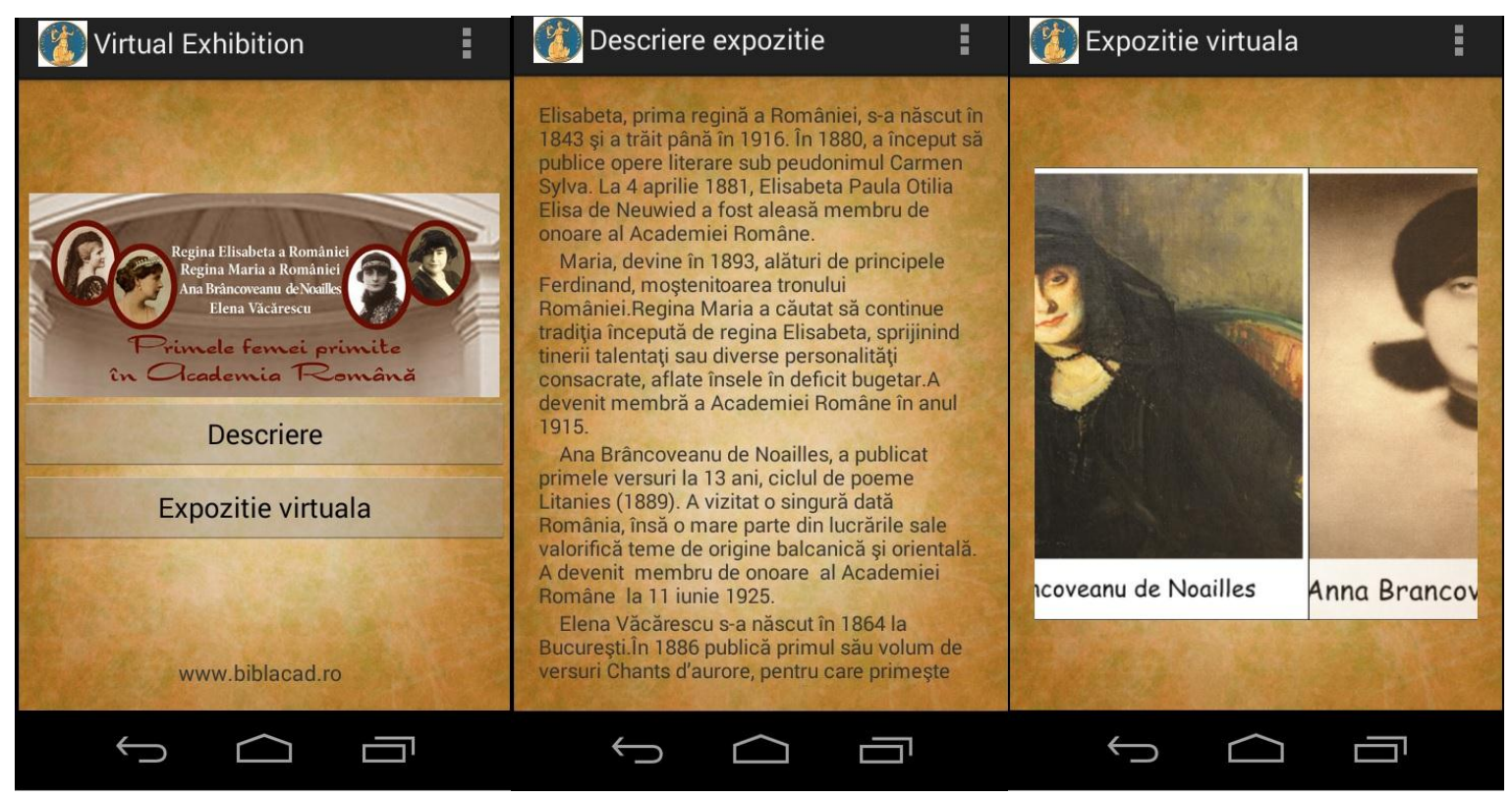

Fig. 5. Mobile virtual exhibition "First women of Romanian Academy"

We must agree that virtual exhibitions are extraordinarily difficult to design and 
develop, mainly because of the number of various stakeholders involved in the process [19] [24].

The good news is that several platforms are already available to achieving multilingual virtual exhibitions. A good example is the MOVIO tool [20] [21], which is largely utilized as a de facto standard in Athena Plus project (www.athenaplus.eu).

\section{Conclusions}

The implementation of mobile applications for virtual exhibitions has the objective to show rare and valuable collections and will witness a significant development in the next years, if we consider the impact they have in the educational and cultural fields.

In the next period, the evolution of mobile technologies will be significant in terms of devices capabilities, operating systems, mobile applications and number of users. Taking this aspect into consideration, it is crucial for any cultural institution to develop at least one mobile application for increasing the visibility and attractiveness of cultural heritage.

The future works on the proposed topic will include researches on the evolution of visitors' number of cultural institutions resulting from investments in digitization and implementation of mobile applications for virtual exhibitions and the relations between actors of economy of culture.

\section{Acknowledgment}

This paper is supported by the Sectorial Operational Programme Human Resources Development (SOP HRD), financed from the European Social Fund and by the Romanian Government under the contract number SOP HRD/159/1.5/S/136077.

\section{References}

[1] C. Ciurea, F. G. Filip, "A Business Model for the Interaction Between Actors of Cultural Economy," Proceedings of the 14th International Conference on Informatics in Economy, IE 2015, 30 April - 03 May 2015, Bucharest,
Romania, ASE Printing House, ISSN 2284-7472, ISSN-L 2247-1480.

[2] P. Clarke, "Tablets: Will They Replace PCs?", Nemertes Research, 2013, Available at: http://i.crn.com/custom/INTELBCCSITE NEW/WhitePaper_Tablets_ReplacePCs.p df

[3] G. Dumitrescu, F. G. Filip, A. Ioniţă, C. Lepădatu, "Open Source Eminescu's Manuscripts: A Digitization Experiment," Studies in Informatics and Control, Vol. 19, No. 1, pp. 79-84.

[4] N. Stroeker, R. Vogels, G. Jan Nauta, M. de Niet, Report on the ENUMERATE Thematic Surveys on Digital Collections in European Cultural Heritage Institutions, September 2013, Available at:

http://www.enumerate.eu/fileadmin/ENU MERATE/documents/ENUMERATE-

Thematic-Survey-2013.pdf

[5] F. G. Filip, C. Ciurea, H. Dragomirescu, I. Ivan, "Cultural Heritage and Modern Information and Communication Technologies," Technological and Economic Development of Economy, Vol. 21, No. 3, May 2015, Taylor \& Francis, pp. 441-459.

[6] F. G. Filip, "Information Technologies in Cultural Institutions," Studies in Informatics and Control, Vol. 6, No. 4, 1996, pp. 385-400.

[7] F. G. Filip, D. A. Donciulescu, C. I. Filip, "A Cybernetic Model of Computerization of the Cultural Heritage," Computer Science Journal of Moldova, Vol. 9, No. 2(26), 2001, pp. 101-112.

[8] EC 2015, Getting cultural heritage to work for Europe, Report of the Horizon 2020 Expert Group on Cultural Heritage, 2015, ISBN 978-92-79-46046-3, Available at: http://www.kowi.de/Portaldata/2/Resource s/horizon2020/coop/H2020-ReportExpert-Group-Cultural-Heritage.pdf

[9] F. G. Filip, "Catre o economie a culturii si o infrastructura informationala intelectuala," Academica, 12 (132), pp. 12-13. 
[10] A. Alzua-Sorzabal, M. T. Linaza, M. Abad, L. Arretxea, A. Susperregui, "Interface Evaluation for Cultural Heritage Applications: the case of FERRUM exhibition," The 6th International Symposium on Virtual Reality, Archaeology and Cultural Heritage (VAST 2005), The Eurographics Association, 2005.

[11] J. Gomes, M. B. Carmo, A. P. Cláudio, "Creating and Assembling Virtual Exhibitions from Existing X3D Models," Docs.DI, 2011.

[12] G. Lepouras, A. Katifori, C. Vassilakis, D. Charitos, "Real exhibitions in a Virtual Museum," Virtual Reality Journal, Springer-Verlag, Vol 7, No 2, 2003, pp. 120-128.

[13] J. Visser, "Museums in times of social and technological change," Innovation, thoughts about museums, 18 April 2014, Available at: http://themuseumofthefuture.com/2014/04 /18/museums-in-times-of-social-andtechnological-change/

[14] C. Ciurea, C. Tudorache, "New Perspectives on the Development of Virtual Exhibitions for Mobile Devices," Economy Informatics, Vol. 14, No. 1/2014, pp. 31-38.

[15] C. Ciurea, C. Coseriu, C. Tudorache, "Implementing Mobile Applications for Virtual Exhibitions using Augmented Reality," Journal of Mobile, Embedded and Distributed Systems, Vol. 6, No. 3, 2014, pp. 96-100.

[16] C. Ciurea, A. Zamfiroiu, A. Grosu, "Implementing Mobile Virtual Exhibition to Increase Cultural Heritage Visibility," Informatica Economică, Vol. 18, No. 2/2014, pp. 24-31.

[17] C. Ciurea, G. Dumitrescu, C. Lepadatu, "The Impact Analysis of Implementing Virtual Exhibitions for Mobile Devices on the Access to National Cultural Heritage," Proceedings of 2nd International Conference 'Economic Scientific Research - Theoretical, Empirical and Practical Approaches', ESPERA 2014,
13-14 November 2014, Bucharest, Romania.

[18] H. G. Wells, World Brain, Methuen \& Co., London, 1938, Available at: https://ebooks.adelaide.edu.au/w/wells/hg/ world_brain/

[19] S. Foo, Y. L. Theng, H.L.D. Goh, J. C. $\mathrm{Na}$, "From Digital Archives to Virtual Exhibitions," Handbook of Research on Digital Libraries: Design, Development and Impact, IGI Global, Hershey, PA, pp. 88-101.

[20] S. H. Minelli, M. T. Natale, B. Dierickx, P. Ongaro, D. Ugoletti, R. Saccoccio, M. Aguilar Santiago, "MOVIO: A semantic content management and valorisation approach for archives and cultural institutions," Girona 2014: Arxius i Indústries Culturals, 2014, Available at: http://www.girona.cat/web/ica2014/ponen ts/textos/id234.pdf

[21] M. T. Natale, S. H. Minelli, B. Dierickx, P. Ongaro, M. Piccininno, D. Ugoletti, R. Saccoccio, A. Raggioli, "Exhibiting Intangible Cultural Heritage using MOVIO: a multilingual toolkit for creating curated digital exhibitions, made available by the AthenaPlus project," ICOM 2014 - Access and Understanding Networking in the Digital Era: intangible Cultural Heritage, 2014, Available at: http://www.cidoc2014.de/images/sampled ata/cidoc/papers/H-2_Natale_Minelli_etal_paper.pdf

[22] V. Bachi, A. Fresa, C. Pierotti, C. Prandoni, "The Digitization Age: Mass Culture Is Quality Culture. Challenges for Cultural Heritage and Society," in Digital Heritage. Progress in Cultural Heritage: Documentation, Preservation, and Protection Lecture Notes in Computer Science, Springer, Vol. 8740, 2014, pp. 786-801.

[23] M. Patel, M. White, K. Walczak, P. Sayd, "Digitisation to Presentation Building Virtual Museum Exhibitions," Vision, Video and Graphics, 2003, Eurographic Digital Library, pp. 189-196.

[24] A. Payne, K. Cole, K. Simon, C. Goodmaster, F. Limp, "Designing the 
Next Generation Virtual Museum: Making 3D Artifacts Available for Viewing and Download," in: Frischer, B., J. Webb Crawford and D. Koller (eds.), Making History Interactive. Computer Applications and Quantitative Methods in Archaeology (CAA). Proceedings of the 37th International Conference, Williamsburg, Virginia, United States of
America, March 22-26, 2010, Archaeopress, Oxford, pp. 292-297.

[25] M. Hagedorn-Saupe, A. Peukert, ,New Ways of Presenting the Past | Work, Research, and Findings of the International Digital Exhibitions Working Group“, Uncommon Culture, Vol. 6, No. 1 (11), 2015, ISSN 2083-0599 (online), 2082-6923 (print), pp. 37-42.

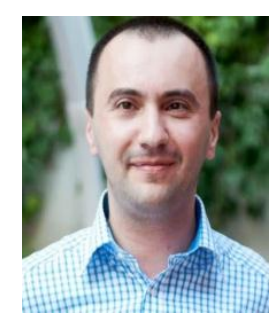

Cristian CIUREA is Assistant Professor at the Department of Economic Informatics and Cybernetics from Bucharest University of Economic Studies. He has graduated the Faculty of Economic Cybernetics, Statistics and Informatics from the Bucharest University of Economic Studies in 2007. He has a master in Informatics Project Management (2010) and a PhD in Economic Informatics (2011) from the Bucharest University of Economic Studies. Cristian has a solid background in computer science and is interested in collaborative systems related issues. Other fields of interest include software metrics, data structures, object oriented programming, windows applications programming, mobile devices programming and testing process automation for software quality assurance.

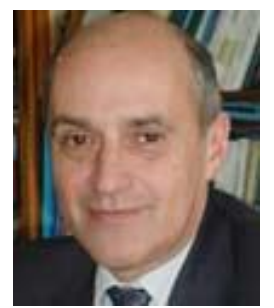

Florin Gheorghe FILIP took his MSc and $\mathrm{PhD}$ in control engineering from the TU "Politehnica" of Bucharest. In $1991 \mathrm{He}$ was elected as a member of the Romanian Academy (RA). He has been a scientific researcher at the National R\&D Institute in Informatics (ICI) of Bucharest. Currently he is a part-time researcher at the National Institute of Economic Researches (INCE) of the RA, also the director of the Library of the Academy. He was elected as vice-president of RA in 2000 and reelected in 2002 and 2006. His main scientific interests include large-scale systems, decision support systems, technology management and foresight. 